\title{
A new leaf and sheath brown spot of foxtail millet caused by Bipolaris australiensis
}

\author{
M. R. Mirzaee ${ }^{\mathrm{A}, \mathrm{C}}$, R. Zare $^{\mathrm{B}}$ and A. Azari Nasrabad ${ }^{\mathrm{A}}$

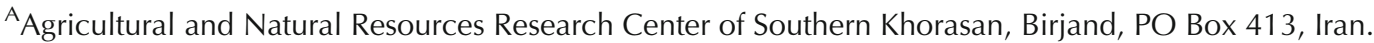 \\ BIranian Research Institute of Plant Protection, PO Box 19395-1454, Tehran, Iran. \\ ${ }^{\mathrm{C} C}$ Corresponding author. Email: reza.mirzaee.mrz@gmail.com
}

\begin{abstract}
A new leaf and sheath spot disease of foxtail millet caused by Bipolaris australiensis was found in Iran. The causal agent was isolated and Koch's postulates were demonstrated. This is the first record of this fungal disease on Setaria italica.
\end{abstract}

Foxtail millet (Setaria italica (L.) Beauv.) is an important staple food for millions of people in southern Europe and Asia (Reddy et al. 2006). In September and October 2008, plants of S. italica with severe and extensive leaf and sheath spots were found in southern Khorasan, Iran. The spots were oblong to irregularly shaped, varying in size, from 3-20 mm in diameter, dark-brown, with a lighter border and an indistinct margin, sometimes causing leaf veins to rupture (Fig. 1). Severe lodging was observed on chronically infected plants. Symptomatic tissues were excised, surface-sterilised in $0.5 \%(\mathrm{v} / \mathrm{v})$ sodium hypochlorite solution, placed onto both potato dextrose agar (PDA) and malt extract agar (MEA) each amended with $250 \mu \mathrm{g} / \mathrm{L}$ carbendazim and incubated at $26^{\circ} \mathrm{C}$ in the dark.

Fungal colonies emerging from the tissue had morphological characteristics typical of Bipolaris spp. Colonies were initially white, but after 3 days turned grey to blackish brown, effuse, velvety and black from the reverse side of the Petri dishes on PDA. Conidiophores were septate, solitary, simple or branched,

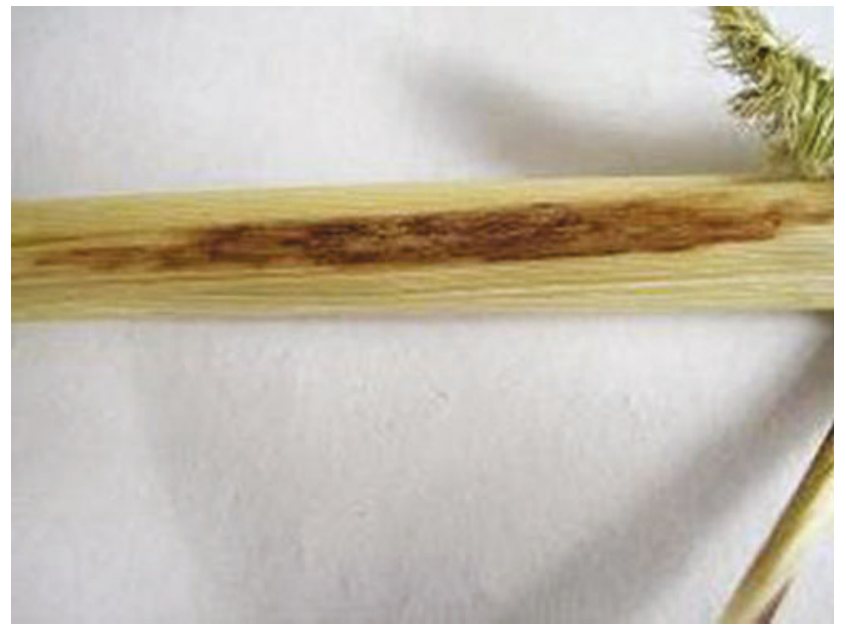

Fig. 1. Leaf-spot symptoms on a foxtail millet leaf. geniculate and sympodial, smooth, reddish brown, 95-205 $\mu \mathrm{m}$ long (average $142 \mu \mathrm{m}$ ), 3-7 $\mu \mathrm{m}$ thick (average $5 \mu \mathrm{m}$ ). Conidia were straight, ellipsoidal or oblong, rounded at the ends, pale brown to reddish brown, mostly three pseudoseptate, mainly $7.5-10.0 \times 15.0-27.5 \mu \mathrm{m}$ in size. A flattened hilum was seen on the basal cell of the conidia (Fig. 2). On the basis of this morphology and the descriptions by Sivanesan (1987), the fungus was identified as B. australiensis (M.B. Ellis) Tsuda \& Ueyama. A culture of $B$. australiensis is preserved at the Iranian Fungal Culture Collection, Tehran, Iran as IRAN 1655C.

Pathogenicity tests were performed separately with two single-spore isolates grown for 15 days on Petri dishes containing one-quarter-strength PDA; 30-day-old foxtail millet seedlings were spray-inoculated with a $20 \mathrm{~mL}$ conidial suspension $\left(10^{5}\right.$ conidia $\left./ \mathrm{mL}\right)$ plus $0.05 \%$ Tween 20 , and placed into closed, translucent, plastic bags lined with wet cotton. Plants were incubated at $22-25^{\circ} \mathrm{C}$ for $48 \mathrm{~h}$ after which time the covers were removed. Control plants received only sterile

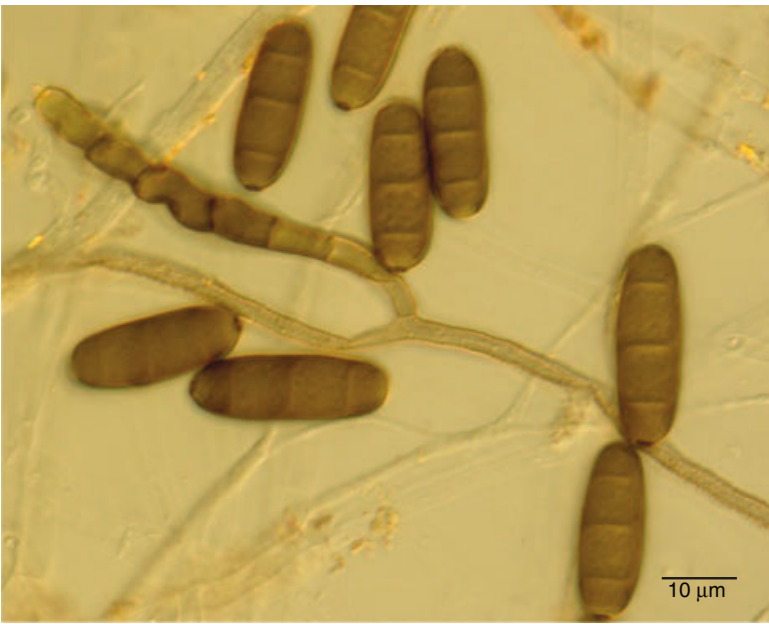

Fig. 2. B. australiensis, conidiophore and conidia. 


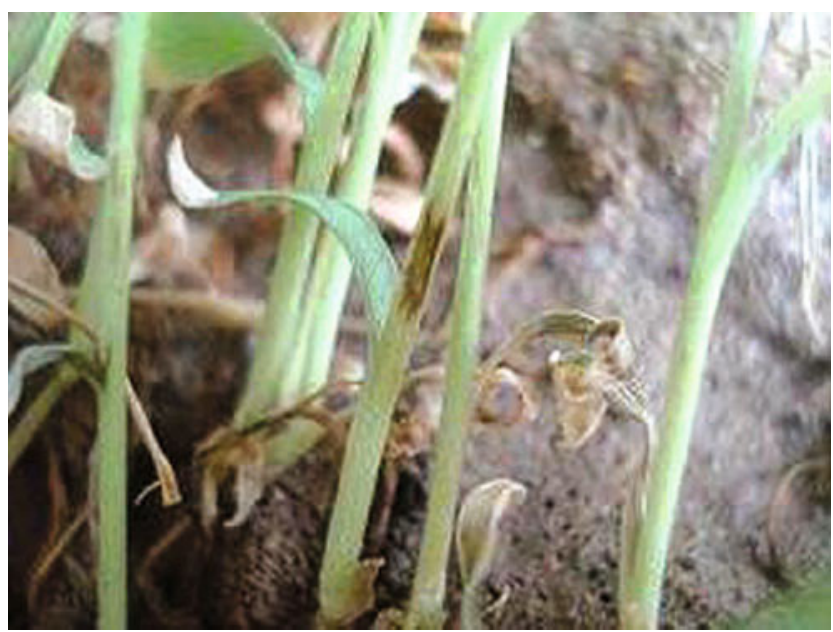

Fig. 3. Pathogenicity test on sheath of foxtail millet, exhibiting brown spot symptoms after 9 days.

distilled water. Disease symptoms similar to those observed in the field appeared after 7-9 days (Fig. 3). No symptoms developed in control treatments and no fungus was isolated from these tissues. $B$. australiensis was reisolated from the induced symptoms fulfilling Koch's postulates.

Bipolaris australiensis has been reported previously to be pathogenic on Chloris and Pennisetum species in Australia, Kenya and India (Smiley et al. 1996; Fang et al. 2007). Further, B. australiensis was reported as the causal agent of brown leaf spot of Cynodon spp. and pearl millet, leaf spot of betelvine (Piper betle) and date palm from China, India, Pakistan and Iraq, respectively (Chand and Singh 1966; Shahzad and Zareen 1999; Fang et al. 2007; Fayad and Mania 2008). This is the first report of $B$. australiensis as a pathogen of foxtail millet.

\section{Acknowledgements}

The authors are grateful to Dr Gh. Haderbadi for his encouragement, Miss A. Ghavipanjah, Mrs. N. Farahmand and Mr. A.Nakhei for their technical assistance.

\section{References}

Chand JN, Singh B (1966) A new Helminthosporium disease of bajra. Current Science 35, 240.

Fang KF, Huang JB, Hsiang T (2007) First report of brown leaf spot caused by Bipolaris australiensis on Cynodon spp. in China. Plant Pathology 56, 349. doi:10.1111/j.1365-3059.2007.01538.x

Fayad MA, Mania AO (2008) Study of date palm leaf spots disease in Basrah and effect of some factors (age of palm, wax content) on infection. Arab Journal of Plant Protection 26, 81-88.

Reddy VG, Upadhyaya HD, Gowda CLL (2006) Characterization of world's foxtail millet germplasm collections for morphological traits. Internet Resource: http://www.icrisat.org/journal/cropimprovement/v2i1/ v2i1characterization.pdf (verified August, 2006).

Shahzad S, Zareen A (1999) Leaf spot of betelvine in Pakistan. Pakistan Journal of Botany 31, 437-443.

Sivanesan A (1987) Graminicolous species of Bipolaris, Curvularia, Drechslera, Exserohilum, and their teleomorphs. Mycological Papers 158, 1-261.

Smiley RW, Dernoeden PH, Clarke BB (1996) 'Compendium of Turfgrass Diseases.' St Paul, MN, APS Press, 98 pp.

Manuscript received 19 January 2010, accepted 12 February 2010 